\title{
Urologic symptoms and burden of frailty and geriatric conditions in older men: the Aging Study of PyeongChang Rural Area
}

\author{
II-Young Jang ${ }^{1,2}$ \\ Chang Ki Lee ${ }^{3}$ \\ Hee-Won Jung ${ }^{4,5}$ \\ Sang Soo $\mathrm{Yu}^{2}$ \\ Young Soo Lee' \\ Eunju Lee' \\ Dae Hyun Kim ${ }^{6,7}$
}

'Department of Internal Medicine, Asan Medical Center, University of Ulsan College of Medicine, Seoul, Republic of Korea; ${ }^{2}$ PyeongChang Health Center \& County Hospital, PyeongChang, Gangwon-Do, Republic of Korea; ${ }^{3}$ Goldman Urology Clinic, Seoul, Republic of Korea; ${ }^{4}$ Graduate School of Medical Science and Engineering, Korea Advanced Institute of Science and Technology (KAIST), Daejeon, Republic of Korea; ${ }^{5}$ Geriatric Center, Seoul National University Bundang Hospital, Seongnam, Gyeonggi-Do, Republic of Korea; ${ }^{6}$ Division of Gerontology, Department of Medicine, Beth Israel Deaconess Medical Center, Boston, MA, USA; ${ }^{7}$ Division of Pharmacoepidemiology and Pharmacoeconomics, Department of Medicine, Brigham and Women's Hospital, Boston, MA, USA
This article was published in the following Dove Press journal: Clinical Interventions in Aging

\begin{abstract}
Purpose: Frailty is an important consideration in the management of lower urinary tract symptoms and erectile dysfunction in older men; frailty increases vulnerability to treatmentrelated adverse outcomes, but its burden is not known. The authors aimed to examine the burden of frailty and associated geriatric conditions in community-dwelling older men.
\end{abstract}

Patients and methods: A cross-sectional study was conducted with 492 community-dwelling older men (mean age, 74.2 years; standard deviation, 5.6 years). All the participants were administered the International Prostate Symptom Score (IPSS) (range: 0-35) and a five-item version of the International Index of Erectile Function (IIEF-5) (range: 5-25). Frailty phenotype was assessed based on exhaustion, inactivity, slowness, weakness, and weight loss. Prevalence of frailty phenotype and geriatric conditions were assessed by the IPSS severity category (mild, 0-7; moderate, 8-19; severe, 20-35 points) and the first IIEF-5 question, which assesses the confidence in erectile function (low, 1-2; moderate, 3; high, 4-5 points).

Results: Older men with severe urologic symptoms had a high prevalence of frailty. According to the IPSS questionnaire, the prevalence of frailty was $7.3 \%(21 / 288)$ in the mild category, $16.3 \%(26 / 160)$ in the moderate category, and $43.2 \%$ (19/44) in the severe category. Participants in the severe IPSS category showed high prevalence of dismobility $(45.5 \%)$, multimorbidity (43.2\%), malnutrition risk (40.9\%), sarcopenia (40.9\%), and polypharmacy (31.8\%). According to erectile confidence based on the first IIEF-5 question, the prevalence of frailty was $18.7 \%$ (56/300) for low confidence, 5.3\% (6/114) for moderate confidence, and 5.1\% (4/78) for high confidence. Participants with low confidence in erectile function showed high prevalence of sarcopenia (39.0\%), multimorbidity (37.7\%), dismobility $(35.7 \%)$, malnutrition risk $(33.3 \%)$, and polypharmacy $(23.0 \%)$.

Conclusion: The prevalence of frailty and geriatric conditions was higher in older men with severe urologic symptoms. A frailty screening should be routinely administered in urology practices to identify older men who are vulnerable to treatment-related adverse events.

Keywords: erectile dysfunction, frailty, geriatric assessment, lower urinary tract symptoms, risk management

\section{Introduction}

Lower urinary tract symptom (LUTS) and erectile dysfunction (ED) are highly prevalent and negatively associated with the quality of life in older men. ${ }^{1}$ The prevalence of moderate to severe LUTS is $46 \%$ in the United States, with an increasing prevalence and severity into the 5 th decade of life. ${ }^{2}$ Meanwhile, ED affects $30 \%$ of men in their $60 \mathrm{~s}^{3}$ and over $80 \%$ of those in their $80 \mathrm{~s}^{4}{ }^{4}$ These symptoms can negatively affect the activity level ${ }^{5}$ and increase the risk of falls. ${ }^{6} \mathrm{ED}$ is also associated with cardiovascular
Department of Internal Medicine, Asan Medical Center, University of Ulsan College of Medicine, 88, Olympic-ro 43-gil, Songpa-gu, Seoul, 05505, Republic of Korea

$\mathrm{Tel}+82230103308$

Fax +82 24760824

Email eunjulee@amc.seoul.kr 
disease, metabolic syndrome, depressive symptoms, and poor quality of life. . $^{7,8}$

While proper treatments of LUTS and ED can improve the well-being of older men, ${ }^{9}$ they are not without risks. ${ }^{6,10,11}$ Medications for LUTS, such as alpha-blockers and antimuscarinics, can worsen orthostatic hypotension and cognitive impairment. ${ }^{10}$ Transurethral resection of the prostate (TURP) can increase the risk of bleeding, delirium, and TURP syndrome, which is associated with morbidity, mortality, prolonged hospitalization, and costs. ${ }^{12,13}$ These risks may be particularly elevated in older men with frailty, ${ }^{14}$ that is, in individuals who have decreased physiologic reserve and increased vulnerability to acute stressors. Therefore, recognizing frailty and geriatric syndromes in older men with urologic symptoms is crucial for the optimal management and prevention of treatment-related adverse events. However, the burden of frailty and geriatric conditions in communitydwelling older men with urologic symptoms is unknown.

We conducted a cross-sectional study to evaluate the burden of frailty and geriatric conditions according to the severity of LUTS and ED in community-dwelling older men. We administered two widely used questionnaires to assess LUTS and ED, the International Prostate Symptom Score (IPSS) and the five-item version of the International Index of Erectile Function (IIEF-5), ${ }^{15,16}$ respectively. We hypothesized that severe symptoms of LUTS and ED are associated with frailty and geriatric syndromes.

\section{Patient and methods Study population}

The Aging Study of PyeongChang Rural Area (ASPRA) is a population-based, prospective cohort study of frailty and geriatric syndromes in 1,350 community-dwelling older adults residing in PyeongChang, Gangwon, Korea. ${ }^{17}$ The design and conduct of ASPRA cohort are described elsewhere. ${ }^{17}$ Briefly, since the cohort was established in October 2014, participants have undergone annual assessments of medical, physical, and psychosocial status. The inclusion criteria for participation in ASPRA were 1 ) age $\geq 65$ years; 2 ) registered in the National Healthcare Service; 3) ambulatory with or without an assistive device; 4) living at home; and 5) able to provide informed consent. Those who were living in a nursing home, hospitalized, or bed-ridden and receiving nursing-home-level care at the time of enrollment were excluded. The study enrolled $95 \%$ of eligible people in the study regions. The characteristics of ASPRA participants were overall similar to those of the Korean rural population represented in the Korea National Health and Nutrition Examination Survey. ${ }^{17}$ Of the total of 498 men who completed the comprehensive geriatric assessment between January 1, 2016 and December 31, 2016, 492 (98.8\%) were assessed for LUTS and ED. The protocol of this study was approved by the Institutional Review Board of the Asan Medical Center. All the participants provided written informed consent.

\section{Urologic questionnaires}

The IPSS and IIEF-5 questionnaires were administered to the participants by male physicians in a privacy-protected area.

\section{IPSS urologic questionnaires}

The IPSS is a widely used questionnaire for screening, diagnosis, and monitoring of the symptoms of benign prostatic hyperplasia and LUTS. ${ }^{15}$ It consists of seven questions regarding voiding symptoms and one question on quality of life, with a scoring range of $0-35$. We classified the participants into mild ( $0-7$ points), moderate (8-19 points), and severe (20-35 points) categories. ${ }^{1}$

\section{IIEF-5}

We evaluated sexual desire (ie, libido) and ED using a fiveitem version of the IIEF (also known as the Sexual Health Inventory for Men $)^{16}$ with a scoring range of 5-25. However, since many participants were not sexually active, we focused on the first IIEF-5 question - "How do you rate your confidence that you could get and keep an erection?" - that assesses the confidence in the erectile function, regardless of their sexual activity. Based on the first IIEF-5 question, we classified the participants as low (1-2 points), moderate (3 points), or high confidence (4-5 points).

\section{Frailty assessment}

Frailty was assessed according to the Cardiovascular Health Study frailty criteria, a widely validated definition for frailty. ${ }^{18}$ The frailty phenotype scale is calculated by assigning 1 point to the following five components that are relevant to a given individual: ${ }^{18} 1$ ) exhaustion: moderate or most of the time during the last week, to either of the following: "I felt that everything I did was an effort" or "I could not get going"; 2) low activity: lowest quintile in physical activity level measured using International Physical Activity Questionnaires Short Form (below the 20th percentile cutoff point in a representative sample of older Koreans in the Korea National Health and Nutrition Examination Survey [KNHANES]); 3) slowness: usual gait speed $<0.8 \mathrm{~m} / \mathrm{s}$ from4-mwalk test; 4) weakness: dominanthandgrip strength $<26 \mathrm{~kg}$ for men, $<17 \mathrm{~kg}$ for women; and 5) weight loss: unintentional weight loss $>3 \mathrm{~kg}$ during previous 6 months. ${ }^{19,20,33}$ On the basis of the total score, individuals were classified as robust (0 points), prefrail (1-2 points), or frail (3-5 points). 


\section{Other measurements}

Trained nurses performed a comprehensive geriatric assessment to evaluate the common geriatric conditions and use of benign prostatic hyperplasia (BPH) medications (alphablockers, 5-alpha-reductase inhibitors, or anticholinergics). Multimorbidity was defined as having five or more of the 11 diagnoses (angina, arthritis, asthma, cancer excluding minor skin cancer, chronic lung disease, congestive heart failure, diabetes, heart attack, hypertension, kidney disease, and stroke). Sarcopenia was defined according to the Asian Working Group for Sarcopenia using a bioimpedance analysis. ${ }^{17}$ Polypharmacy was defined as taking five or more prescription medications. Low cognition was defined as a Korean version of Mini-Mental-State Examination score $<24 .{ }^{21}$ Depressive mood was defined as a Korean version of the Center for Epidemiological Studies Depression scale score $>20 .{ }^{22}$ Slow gait was defined as a usual gait speed $<0.6 \mathrm{~m} / \mathrm{s}$ from a timed 4-m walk. ${ }^{23}$ Malnutrition risk was defined as a score of $\leq 11$ according to the Mini-Nutritional Assessment-Short Form. ${ }^{24}$ Disability was defined as requiring assistance in performing any of the seven activities of daily living (ADL; bathing, continence, dressing, eating, toileting, transferring, and washing face and hands) or 10 instrumental activities of daily living (IADL; food preparation, household chores, going out a short distance, grooming, handling finances, laundry, managing own medications, shopping, transportation, and using a telephone). ${ }^{25}$

\section{Statistical analysis}

We summarized the characteristics of our study participants according to the mean and standard deviation (SD) for continuous variables and proportions for categorical variables. We evaluated the prevalence of the frailty phenotype and its components according to the severity categories of the IPSS and the first IIEF-5 question. The proportion of frailty and its component was compared across the severity category using a logistic regression to adjust for age. The odds ratio (OR) and $95 \%$ confidence interval (CI) of frailty across the severity category were also estimated. Statistical analyses were performed using SPSS version 21.0 (IBM Corporation, Armonk, NY, USA). A two-sided $p$-value $<0.05$ was considered statistically significant.

\section{Results}

\section{Characteristics of study participants}

The mean age of the 492 men was 74.2 years (standard deviation: 5.6) (Table 1). Most men were prefrail (73.2\%) or frail (13.4\%), and multimorbidity (32.5\%), low cognition
Table I Characteristics of male participants in the Aging Study of PyeongChang Rural Area

\begin{tabular}{|c|c|}
\hline Characteristics & $\begin{array}{l}\mathbf{N}(\%) \text { or } \\
\text { mean } \pm \text { SD }\end{array}$ \\
\hline Sample size & 492 \\
\hline \multicolumn{2}{|l|}{ IPSS (range: 0-35 points) } \\
\hline Mild (IPSS 0-7 points) & $288(58.5)$ \\
\hline Moderate (IPSS 8-19 points) & $160(32.5)$ \\
\hline Severe (IPSS $20-35$ points) & $44(8.9)$ \\
\hline On BPH medication & $117(23.8)$ \\
\hline \multicolumn{2}{|l|}{ IIEF-5 (range: 5-25 points) } \\
\hline Normal to mild (IIEF I7-25 points) & $103(20.9)$ \\
\hline Mild to moderate (IIEF 12-16 points) & $83(16.9)$ \\
\hline Moderate to severe (IIEF 5-II points) & $68(13.8)$ \\
\hline No sex partner or sexual behavior (IIEF I-4 points) & $238(48.4)$ \\
\hline \multicolumn{2}{|l|}{ First IIEF-5 question (range: I-5 points) } \\
\hline Low erectile confidence ( 1 or 2 points) & $300(6 I)$ \\
\hline Moderate erectile confidence ( 3 points) & $114(23.2)$ \\
\hline High erectile confidence ( 4 or 5 points) & $78(15.9)$ \\
\hline Age, years & $74.2 \pm 5.6$ \\
\hline \multicolumn{2}{|l|}{ CHS frailty phenotype } \\
\hline Robust & $66(13.4)$ \\
\hline Prefrail & $360(73.2)$ \\
\hline Frail & $66(13.4)$ \\
\hline Multimorbidity & $160(32.5)$ \\
\hline Hypertension & $240(48.8)$ \\
\hline Arthritis & III (22.6) \\
\hline Diabetes & $85(17.3)$ \\
\hline Heart disease & $55(11.2)$ \\
\hline Chronic lung disease & $37(7.5)$ \\
\hline Sarcopenia & $164(33.3)$ \\
\hline Polypharmacy & 91 (18.5) \\
\hline MMSE $<24$ & $82(16.7)$ \\
\hline Depression & $12(2.4)$ \\
\hline SPPB score & $8.7 \pm 2.2$ \\
\hline Dismobility & $160(32.5)$ \\
\hline Fall in past year & $64(13)$ \\
\hline At risk of malnutrition & $135(27.4)$ \\
\hline ADL disability & 41 (8.3) \\
\hline IADL disability & 77 (I5.7) \\
\hline
\end{tabular}

Abbreviations: $A D L$, activities of daily living; $B P H$, benign prostatic hyperplasia; CHS, Cardiovascular Health Study; IADL, instrumental activities of daily living; IIEF-5, five-item version of International Index of Erectile Function; IPSS, International Prostate Symptom Score; MMSE, mini-mental-state examination; SPPB, short physical performance battery.

(16.7\%), IADL disability (15.7\%), and fall history (13.0\%) were common. The most prevalent underlying diseases diagnosed by physicians were hypertension (48.8\%), arthritis (22.6\%), diabetes $(17.3 \%)$, heart disease $(11.2 \%)$ and chronic lung disease (7.5\%). Alpha-blockers, 5-alpha-reductase inhibitors, or anticholinergics were used by 117 men (23.8\%). The IPSS questionnaire classified 288 men (58.5\%) as mild, $160(32.5 \%)$ as moderate, and $44(8.9 \%)$ as severe for LUTS symptoms. According to the first IIEF-5 question, which assesses the confidence in erectile function, 300 men (61.0\%) had low confidence. 


\section{Frailty and its components by IPSS and the first IIEF-5 question scores}

The prevalence of frail and prefrail states increased with greater IPSS severity (Figure 1A). Frailty was present in 21 of the 288 men $(7.3 \%)$ with mild symptoms, 26 of the 160 men (16.3\%) with moderate symptoms (OR: 2.47; 95\% CI: $1.34-4.55 ; p=0.004)$, and 19 of the 44 men $(43.2 \%)$ with severe symptoms (OR: 9.66; 95\% CI: 4.59-20.33; $p<0.001)$. Similarly, the prevalence of frailty was higher in the lower erectile confidence categories according to the first IIEF-5 question (Figure 1B). Frailty was identified in four of 78 men with high confidence (5.1\%), six of 114 men $(5.3 \%)$ with moderate confidence (OR: 1.03 ; 95\% CI: 0.28-3.77; $p=0.967)$, and 56 of 300 men $(18.7 \%)$ with low confidence (OR: 4.25; 95\% CI: 1.49-12.10; $p=0.007)$. Each component of frailty increased in prevalence with higher severity according to IPSS (Figure 2A) or the first IIEF-5 question (Figure 2B).

\section{Common geriatric conditions according to IPSS and the first IIEF-5 question scores}

We also investigated the common geriatric conditions according to the severity as determined by each urologic questionnaire (Table 2). The prevalence of most geriatric conditions was higher as the severity of LUTS increased.
Close to a half of the individuals with severe IPSS symptoms had dismobility (45.5\%), multimorbidity (43.2\%), malnutrition risk $(40.9 \%)$, or sarcopenia $(40.9 \%)$. The severe LUTS group showed significantly high prevalence of multimorbidity (43.2\% of severe LUTS group; $43.1 \%$ of moderate group; $25.0 \%$ of mild group; $p<0.001$ ), polypharmacy $(31.8 \%$ of severe LUTS group; $21.3 \%$ of moderate group; $14.9 \%$ in mild group; $p=0.015)$, and the mean number of regular medications taken regularly (3.6 tablets [SD 3.5] in severe LUTS group; 2.7 tablets [SD 2.7] in moderate group; 2.0 tablets [SD 2.4] in mild group, $p<0.001$ ) than low LUTS group.

Similarly, geriatric conditions were more prevalent in those with low erectile confidence: sarcopenia (39.0\%), multimorbidity (37.7\%), dismobility (35.7\%), and malnutrition risk $(33.3 \%)$ were common. Compared to the group of high confidence of erectile function, the group of low confidence of erectile function showed significantly high prevalence of multimorbidity $37.7 \%$ in the group of low confidence of erectile function; $24.6 \%$ in the group of moderate confidence; $24.4 \%$ in the group of high confidence; $p=0.010$ ), polypharmacy $(23.0 \%$ in the group of low confidence of erectile function; $11.4 \%$ in the group of moderate confidence; $11.5 \%$ in the group of high confidence; $p=0.006)$, and the mean number of medications taken regularly (2.8 tablets [SD 2.9] in the group of low confidence of erectile function; 1.8 tablets [SD 2.2]
A

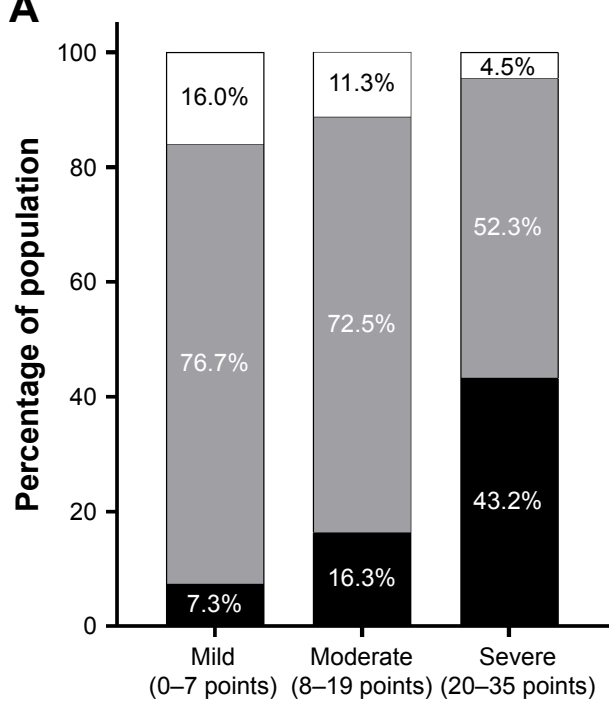

B

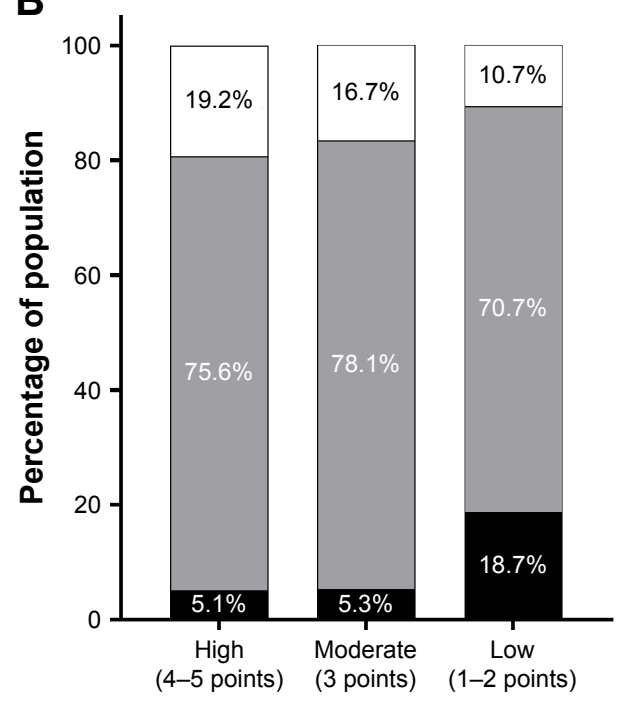

Robust $\square$ Prefrail

Figure I Frailty status according to IPSS category (A) and the first IIEF-5 question (B).

Notes: IIEF-5 first question asks participants, "How do you rate your confidence that you could get and keep an erection?" (A) LUTS from IPSS category; (B) Erectile confidence from the first IIEF-5 question; Frailty status was defined by Cardiovascular Health Study frailty criteria. We defined 0-7 points of IPSS score as "mild", 8-19 points as "moderate", and 20-35 points as "severe" LUTS. We also defined 4 or 5 points of the first IIEF-5 question as "high", 3 points as "moderate", and I or 2 as "low" erectile confidence.

Abbreviations: IPSS, International Prostate Symptom Score; IIEF-5, five-item version of International Index of Erectile Function; LUTS, lower urinary tract symptom. 

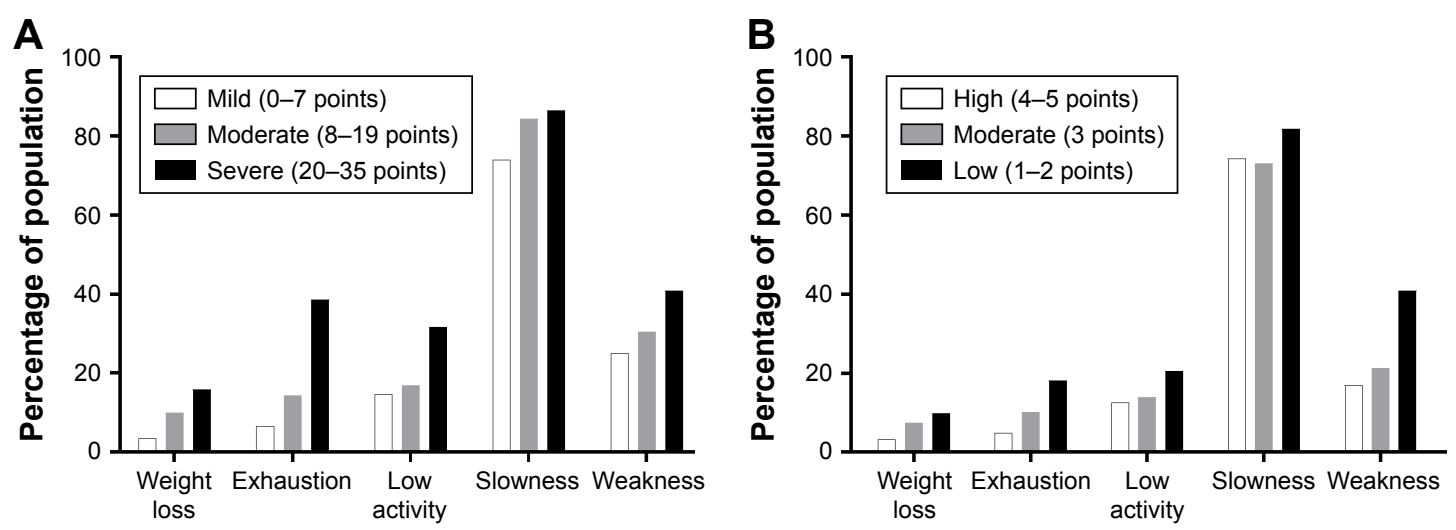

Figure 2 Frailty components according to IPSS category (A) and the first IIEF-5 question (B).

Notes: The first IIEF-5 question asks participants, "How do you rate your confidence that you could get and keep an erection?" (A) LUTS from IPSS category; (B) Erectile confidence from the first IIEF-5 question; Frailty components originated from Cardiovascular Health Study frailty criteria. We defined 0-7 points of IPSS score as "mild", 8-19 points as "moderate", and 20-35 points as "severe" LUTS. We also defined 4 or 5 points of the first IIEF-5 question as "high", 3 points as "moderate", and I or 2 as "low" erectile confidence.

Abbreviations: IPSS, International Prostate Symptom Score; IIEF-5, five-item version of International Index of Erectile Function; LUTS, lower urinary tract symptom.

in the group of moderate confidence; 2.7 tablets [SD 2.1] in the group of high confidence; $p<0.001)$.

\section{Discussion}

A majority of patients seeking medical or surgical treatment for moderate or severe LUTS are older men, and our study indicates that almost a half of these patients satisfy the criteria for frailty. Given that frail older adults may have increased vulnerability to treatment-related adverse events, our findings suggest the importance of recognizing frailty in older men with severe LUTS symptoms through a validated frailty assessment in the management of urological symptoms in these patients.

Medications are a primary treatment option in older men with moderate to severe LUTS. However, several medications used to treat LUTS can increase the risks of confusion, falls, and possibly mortality. ${ }^{10,14}$ Alpha-1 blockers, especially doxazosin, terazosin, and prazosin, should be avoided in older

Table 2 Common geriatric syndromes according to IPSS category and first IIEF-5 question in the Aging Study of PyeongChang Rural Area

\begin{tabular}{|c|c|c|c|c|c|c|c|c|}
\hline \multirow[t]{3}{*}{ Geriatric syndrome } & \multicolumn{3}{|c|}{ LUTS from IPSS category } & \multirow[t]{3}{*}{ p-value } & \multicolumn{3}{|c|}{$\begin{array}{l}\text { Erectile confidence from first IIEF-5 } \\
\text { question }\end{array}$} & \multirow[t]{3}{*}{$p$-value } \\
\hline & $\begin{array}{l}\text { Mild } \\
\text { (0-7 points) }\end{array}$ & $\begin{array}{l}\text { Moderate } \\
\text { (8-19 points) }\end{array}$ & $\begin{array}{l}\text { Severe } \\
\text { (20-35 points) }\end{array}$ & & $\begin{array}{l}\text { High } \\
\text { (4-5 points) }\end{array}$ & $\begin{array}{l}\text { Moderate } \\
\text { ( } 3 \text { points) }\end{array}$ & $\begin{array}{l}\text { Low } \\
\text { (I-2 points) }\end{array}$ & \\
\hline & $\begin{array}{l}\mathbf{N}(\%) \text { or } \\
\text { mean } \pm \mathbf{S D} \\
(\mathbf{N}=\mathbf{2 8 8})\end{array}$ & $\begin{array}{l}\mathbf{N}(\%) \text { or } \\
\text { mean } \pm S D \\
(N=160)\end{array}$ & $\begin{array}{l}\mathbf{N}(\%) \text { or } \\
\text { mean } \pm \text { SD } \\
(\mathbf{N}=44)\end{array}$ & & $\begin{array}{l}\mathbf{N}(\%) \text { or } \\
\text { mean } \pm S D \\
(\mathbf{N}=44)\end{array}$ & $\begin{array}{l}\mathbf{N}(\%) \text { or } \\
\text { mean } \pm S D \\
(\mathbf{N}=|| 4)\end{array}$ & $\begin{array}{l}\mathbf{N}(\%) \text { or } \\
\text { mean } \pm \mathbf{S D} \\
(\mathbf{N}=\mathbf{3 0 0})\end{array}$ & \\
\hline Multimorbidity & $72(25.0)$ & $69(43.1)$ & $19(43.2)$ & $<0.001$ & $19(24.4)$ & $28(24.6)$ & $113(37.7)$ & 0.010 \\
\hline Sarcopenia & $88(30.6)$ & $58(36.3)$ & $18(40.9)$ & 0.254 & II (14.1) & $36(31.6)$ & $117(39.0)$ & $<0.001$ \\
\hline Polypharmacy & $43(14.9)$ & $34(21.3)$ & $14(3 \mid .8)$ & 0.015 & $9(11.5)$ & I3 (II.4) & $69(23.0)$ & 0.006 \\
\hline $\begin{array}{l}\text { Number of medications } \\
\text { taken regularly }\end{array}$ & $2.0 \pm 2.4$ & $2.7 \pm 2.7$ & $3.6 \pm 3.5$ & $<0.001$ & $1.7 \pm 2.1$ & $1.8 \pm 2.2$ & $2.8 \pm 2.9$ & $<0.001$ \\
\hline MMSE $<24$ & $40(13.9)$ & $30(18.8)$ & $12(27.3)$ & 0.059 & $9(11.5)$ & $15(13.2)$ & $58(19.3)$ & 0.134 \\
\hline Depression & $2(0.7)$ & $6(3.8)$ & $4(9.1)$ & 0.001 & $0(0)$ & $\mathrm{I}(0.9)$ & II (3.7) & 0.082 \\
\hline SPPB score & $9.0 \pm 2.0$ & $8.1 \pm 2.3$ & $7.8 \pm 2.7$ & $<0.001$ & $9.3 \pm 1.6$ & $9.2 \pm 2.0$ & $8.3 \pm 2.4$ & $<0.001$ \\
\hline Dismobility & $79(27.4)$ & $61(38.1)$ & $20(45.5)$ & 0.011 & $19(24.4)$ & $34(29.8)$ & $107(35.7)$ & 0.129 \\
\hline Fall in past year & $33(11.5)$ & $23(14.4)$ & $8(18.2)$ & 0.385 & $13(16.7)$ & $9(7.9)$ & $42(14.0)$ & 0.149 \\
\hline At risk of malnutrition & $84(29.2)$ & $56(35.0)$ & $18(40.9)$ & 0.191 & $28(35.9)$ & $30(26.3)$ & $100(33.3)$ & 0.291 \\
\hline ADL disability & $8(2.8)$ & $23(14.4)$ & $10(22.7)$ & $<0.001$ & $3(3.8)$ & $3(2.6)$ & 35 (1I.7) & 0.003 \\
\hline IADL disability & $32(I I . I)$ & $35(21.9)$ & $10(22.7)$ & 0.004 & $8(10.3)$ & $8(7.0)$ & $6 \mathrm{I}(20.3)$ & 0.001 \\
\hline
\end{tabular}

Note: The first IIEF-5 question asks participants, "How do you rate your confidence that you could get and keep an erection?"

Abbreviations: ADL, activities of daily living; IADL, instrumental activities of daily living; IIEF-5, five-item version of International Index of Erectile Function; IPSS, International Prostate Symptom Score; LUTS, lower urinary tract symptom; MMSE, mini-mental-state examination; SPPB, short physical performance battery. 
men with syncope, due to the risk of orthostatic hypotension. Antimuscarinics such as oxybutynin should be avoided in older patients with delirium, cognitive impairment, dementia, and Parkinson disease, due to their strong anticholinergic effects. Desmopressin, often used to treat nocturia or nocturnal polyuria, can increase the risk of hyponatremia. Based on these facts, the 2015 American Geriatric Society Beers Criteria recommended these medications be avoided or used with caution. ${ }^{26}$ Oelke et al also warned of the potential harm of LUTS medication based on efficacy, safety, and tolerability. ${ }^{10}$ In treating ED, discontinuation of certain culprit medications, such as antidepressants, diuretics, and beta-blockers, can help ED, but it might also exacerbate the comorbidity conditions. ${ }^{27}$ Phosphodiesterase-5 inhibitors should be prescribed with caution in men with angina or coronary artery disease, which, it should be noted, are often undiagnosed in older patients. Dyspepsia, headache, flushing, visual disturbance, and drug-food interactions, meanwhile, are other potentially important issues. ${ }^{27}$ According to several reports and experts, the risk of these adverse events may be higher in frail older adults. ${ }^{28-30}$

In cases where medications are not effective, surgical procedures are considered. Surgical procedures in older men, however, can be associated with adverse events. Approximately $15 \%-20 \%$ of patients undergoing TURP experience significant complications such as bleeding, clot retention, perforation of the prostate capsule, urinary tract infection, and post prostatectomy syndrome, and $0.2 \%-2.5 \%$ die. ${ }^{13}$ In a Veterans Administration study, $9 \%$ of subjects had perioperative complications, including the need for placement of another urinary catheter, perforation of the prostate capsule, hemorrhage requiring transfusion, urinary tract infections, and thrombophlebitis. ${ }^{31}$ Other studies have revealed that older men were more likely than younger men to develop TURP syndrome and delirium. ${ }^{12}$ These complications negatively affect the quality of life and increase medical costs. ${ }^{13}$ Frailty was strongly associated with the risk of postoperative complications after nearly all urologic surgery or procedures (adjusted OR 1.74; 95\% CI: 1.64-1.85). ${ }^{14,32}$

Because frail older men may be at high risk of adverse events from LUTS or ED treatment, our results indicate the importance of recognizing frailty in the management of common urological symptoms in older men. In geriatrics, a number of frailty instruments have been developed and validated. Some of the widely validated instruments include the frailty phenotype, a deficit accumulation of frailty index, and the FRAIL (Fatigue, Resistance, Ambulation, Illnesses, Loss of weight) scale. The frailty phenotype that we used was developed from a large community-based cohort of older adults in the United States ${ }^{18,32}$ and subsequently validated in several other populations. ${ }^{33-35}$ It is based on the assessment of five specific components that require certain skills and administration time (in our experience, 10-15 minutes). The frailty index developed by Rockwood and Mitnitski originated from a large population-based Canadian cohort. ${ }^{36}$ It calculates the proportion of deficits from a total of 30-90 health deficit variables. Rather than these extensive evaluations, we recommend that urologists and primary care physicians adopt the FRAIL scale, which is a brief screening tool based on five self-reported items. ${ }^{37}$ This has been validated for the US, ${ }^{37}$ European, ${ }^{38}$ and Asian populations. ${ }^{39}$ It classifies participants as robust ( 0 points), prefrail (1-2 points), or frail (3-5 points). This questionnaire does not require a physical examination and can be administered within 3 minutes. ${ }^{39}$ Frailty screening improves prediction of older adults at high risk for poor surgical outcomes, ${ }^{40-43}$ but few studies examined this in older men undergoing urological procedures. ${ }^{14,32}$ Further studies are warranted to define the role of frailty screening in determining the risk-benefit of the urological procedures in older men.

There are several strengths and limitations to our study. The ASPRA is a population-based prospective cohort study that administered standardized measurements for frailty and an extensive list of geriatric syndromes in addition to the IPSS and IIEF-5 questionnaires. ${ }^{17}$ Because our study population had a high participation rate of eligible men residing in the study regions, selection bias due to non-participation is unlikely. Although the ASPRA cohort was based on a rural community in Korea, we previously showed that their demographic characteristics are similar to a nationally representative sample. ${ }^{17}$ However, the results from this study may not be generalized to nursing homes or populations of other ethnic origins. As a cross-sectional study, we were not able to determine whether the IPSS scores and the response to the first IIEF-5 question can predict the future development of frailty in older men and whether frailty can predict the worsening of urological symptoms in the future. The longterm follow-up data from the ASPRA cohort will be valuable to answer these clinically important questions.

\section{Conclusion}

Our study underscores the high prevalence of frailty and geriatric syndromes in older men with severe LUTS or ED. Considering the high prevalence of frailty and its clinical implications, urologists and primary care physicians should consider adopting a simple frailty screening tool for 
identifying frail older patients who may require careful assessment of benefits and risks of medical and surgical management options for their urological symptoms. Future research on whether a frailty screening and subsequent management based on frailty assessment improve patient-centered care and clinical outcomes in these patients is needed.

\section{Acknowledgments}

We are indebted to public health professionals and nurses of PyeongChang County Hospital, Public Health Center, and Community Health Posts for their administrative support and effort in enrollment and measurements. Public health professionals and nurses of PyeongChang County Hospital were involved in data collection, but they did not have any role in the study design, analysis or interpretation of data, writing of the paper, or decision to submit the paper for publication.

The ASPRA was supported by PyeongChang County Hospital, PyeongChang County, Gangwon Province, Korea. This study was also supported, in part, by Paul Park and Maeil Dairies Co., Ltd., and by the Asan Institute for Life Sciences and Corporate Relations of the Asan Medical Center, Seoul, Korea. Paul Park and Maeil Dairies Co., Ltd., and the Asan Medical Center did not have any role in the study design, data collection, analysis or interpretation of the data, writing of the paper, or decision to submit the paper for publication.

Dr Hee-Won Jung is supported by a Global PhD Fellowship Program through the National Research Foundation of Korea funded by the Ministry of Education (NRF-2015H1A2A1030117). Dr Dae Hyun Kim is supported by the Paul B Beeson Clinical Scientist Development Award in Aging (K08AG051187) from the National Institute on Aging, American Federation for Aging Research, The John A Hartford Foundation, and The Atlantic Philanthropies.

\section{Author contributions}

All the authors participated in design and study conception, performed statistical analysis, data analysis and interpretation, and drafted the manuscript. All the authors read and revised this manuscript. This manuscript is the final approved version by all authors. All the authors have reviewed and agreed to be responsible for the process, accuracy, and integrity of all the parts of this manuscript.

\section{Disclosure}

Dr Dae Hyun Kim is a consultant to Alosa Health, a nonprofit educational organization with no relationship to any drug or device manufacturer. The other authors report no conflicts of interest in this work.

\section{References}

1. Sagnier PP, MacFarlane G, Teillac P, Botto H, Richard F, Boyle P. Impact of symptoms of prostatism on level of bother and quality of life of men in the French community. J Urol. 1995;153(3 Pt 1): 669-673.

2. Taylor BC, Wilt TJ, Fink HA, et al. Prevalence, severity, and health correlates of lower urinary tract symptoms among older men: the MrOS study. Urology. 2006;68(4):804-809.

3. Rosen RC, Fisher WA, Eardley I, et al. The multinational men's attitudes to life events and sexuality (MALES) study: I. Prevalence of erectile dysfunction and related health concerns in the general population. Curr Med Res Opin. 2004;20(5):607-617.

4. Seftel AD. Erectile dysfunction in the elderly: epidemiology, etiology and approaches to treatment. J Urol. 2003;169(6):1999-2007.

5. Hunter DJ, McKee M, Black NA, Sanderson CF. Health status and quality of life of British men with lower urinary tract symptoms: results from the SF-36. Urology. 1995;45(6):962-971.

6. Morris V, Wagg A. Lower urinary tract symptoms, incontinence and falls in elderly people: time for an intervention study. Int J Clin Pract. 2007;61(2):320-323.

7. Malavige LS, Jayaratne SD, Kathriarachchi ST, Sivayogan S, Ranasinghe P, Levy JC. Erectile dysfunction is a strong predictor of poor quality of life in men with type 2 diabetes mellitus. Diabet med. 2014; 31(6):699-706.

8. Sanchez E, Pastuszak AW, Khera M. Erectile dysfunction, metabolic syndrome, and cardiovascular risks: facts and controversies. Transl Androl Urol. 2017;6(1):28-36.

9. Arai Y, Aoki Y, Okubo K, et al. Impact of interventional therapy for benign prostatic hyperplasia on quality of life and sexual function: a prospective study. J Urol. 2000;164(4):1206-1211.

10. Oelke M, Becher K, Castro-Diaz D, et al. Appropriateness of oral drugs for long-term treatment of lower urinary tract symptoms in older persons: results of a systematic literature review and international consensus validation process (LUTS-FORTA 2014). Age Ageing. 2015; 44(5):745-755.

11. Lucenteforte E, Lombardi N, Vetrano DL, et al. Inappropriate pharmacological treatment in older adults affected by cardiovascular disease and other chronic comorbidities: a systematic literature review to identify potentially inappropriate prescription indicators. Clin Interv Aging. 2017;12:1761-1778.

12. Xue $\mathrm{P}, \mathrm{Wu} \mathrm{Z}$, Wang $\mathrm{K}, \mathrm{Tu} \mathrm{C}$, Wang $\mathrm{X}$. Incidence and risk factors of postoperative delirium in elderly patients undergoing transurethral resection of prostate: a prospective cohort study. Neuropsychiatr Dis Treat. 2016;12:137-142.

13. Rieken M, Ebinger Mundorff N, Bonkat G, Wyler S, Bachmann A. Complications of laser prostatectomy: a review of recent data. World J Urol. 2010;28(1):53-62.

14. Suskind AM, Walter LC, Jin C, et al. Impact of frailty on complications in patients undergoing common urological procedures: a study from the American College of Surgeons National Surgical Quality Improvement database. BJU Int. 2016;117(5):836-842.

15. Abrams P, Chapple C, Khoury S, et al. Evaluation and treatment of lower urinary tract symptoms in older men. J Urol. 2013;189(1 Suppl): S93-S101.

16. Rosen RC, Cappelleri JC, Smith MD, Lipsky J, Pena BM. Development and evaluation of an abridged, 5 -item version of the International Index of Erectile Function (IIEF-5) as a diagnostic tool for erectile dysfunction. Int J Impot Res. 1999;11(6):319-326.

17. Jung HW, Jang IY, Lee YS, et al. Prevalence of frailty and aging-related health conditions in older Koreans in rural communities: a crosssectional analysis of the Aging Study of Pyeongchang Rural Area. J Korean Med Sci. 2016;31(3):345-352. 
18. Fried LP, Tangen CM, Walston J, et al. Frailty in older adults: evidence for a phenotype. J Gerontol A Biol Sci Med Sci. 2001;56(3): M146-M156.

19. Avila-Funes JA, Amieva H, Barberger-Gateau P, et al. Cognitive impairment improves the predictive validity of the phenotype of frailty for adverse health outcomes: the three-city study. J Am Geriatr Soc. 2009; 57(3):453-461.

20. Fukutomi E, Okumiya K, Wada T, et al. Importance of cognitive assessment as part of the "Kihon Checklist" developed by the Japanese Ministry of Health, Labor and Welfare for prediction of frailty at a 2-year follow up. Geriatr Gerontol Int. 2013;13(3):654-662.

21. Kang Y, Na DL, Hahn S. A validity study on the Korean Mini-Mental State Examination (K-MMSE) in dementia patients. J Korean Neurol Assoc. 1997;15(2):300-308.

22. Park JH, Kim KW. A review of the epidemiology of depression in Korea. J Korean Med Assoc. 2011;54(4):362-369.

23. Cummings SR, Studenski S, Ferrucci L. A diagnosis of dismobility giving mobility clinical visibility: a Mobility Working Group recommendation. JAMA. 2014;311(20):2061-2062.

24. Rubenstein LZ, Harker JO, Salva A, Guigoz Y, Vellas B. Screening for undernutrition in geriatric practice: developing the short-form mini-nutritional assessment (MNA-SF). J Gerontol A Biol Sci Med Sci. 2001;56(6):M366-M372.

25. Won CW, Yang KY, Rho YG, et al. The Development of Korean Activities of Daily Living (K-ADL) and Korean Instrumental Activities of Daily Living (K-IADL) Scale. J Korean Geriatr Soc. 2002;6(2):107-120.

26. By the American Geriatrics Society 2015 Beers Criteria Update Expert Panel. American Geriatrics Society 2015 updated beers criteria for potentially inappropriate medication use in older adults. $J$ Am Geriatr Soc. 2015;63(11):2227-2246.

27. Fink HA, Mac Donald R, Rutks IR, Nelson DB, Wilt TJ. Sildenafil for male erectile dysfunction: a systematic review and meta-analysis. Arch Intern Med. 2002;162(12):1349-1360.

28. Wagg A, Gibson W, Ostaszkiewicz J, et al. Urinary incontinence in frail elderly persons: Report from the 5th International Consultation on Incontinence. Neurourol Urodyn. 2015;34(5):398-406.

29. Tannenbaum C. How to treat the frail elderly: the challenge of multimorbidity and polypharmacy. Can Urol Assoc J. 2013;7(9-10 Suppl 4): S183-S185.

30. Landi F, Russo A, Liperoti R, et al. Anticholinergic drugs and physical function among frail elderly population. Clin Pharmacol Ther. 2007; 81(2):235-241.
31. Wasson JH, Reda DJ, Bruskewitz RC, Elinson J, Keller AM, Henderson WG. A comparison of transurethral surgery with watchful waiting for moderate symptoms of benign prostatic hyperplasia. The Veterans Affairs Cooperative Study Group on Transurethral Resection of the Prostate. N Engl J Med. 1995;332(2):75-79.

32. Clegg A, Young J, Iliffe S, Rikkert MO, Rockwood K. Frailty in elderly people. Lancet. 2013;381(9868):752-762.

33. Jung HW, Kim SW, Ahn S, et al. Prevalence and outcomes of frailty in Korean elderly population: comparisons of a multidimensional frailty index with two phenotype models. PLoS One. 2014;9(2):e87958.

34. Garcia-Garcia FJ, Gutierrez Avila G, Alfaro-Acha A, et al. The prevalence of frailty syndrome in an older population from Spain. The Toledo Study for Healthy Aging. J Nutr Health Aging. 2011;15(10): 852-856.

35. Bieniek J, Wilczynski K, Szewieczek J. Fried frailty phenotype assessment components as applied to geriatric inpatients. Clin Interv Aging. 2016;11:453-459.

36. Rockwood K, Mitnitski A. Frailty in relation to the accumulation of deficits. J Gerontol A Biol Sci Med Sci. 2007;62(7):722-727.

37. Morley JE, Malmstrom TK, Miller DK. A simple frailty questionnaire (FRAIL) predicts outcomes in middle aged African Americans. J Nutr Health Aging. 2012;16(7):601-608.

38. Brooks R. EuroQol: the current state of play. Health Policy. 1996;37(1): 53-72.

39. Jung HW, Yoo HJ, Park SY, et al. The Korean version of the FRAIL scale: clinical feasibility and validity of assessing the frailty status of Korean elderly. Korean J Intern Med. 2016;31(3):594-600.

40. Lin HS, Watts JN, Peel NM, Hubbard RE. Frailty and post-operative outcomes in older surgical patients: a systematic review. BMC Geriatr. 2016;16(1):157.

41. Hall DE, Arya S, Schmid KK, et al. Association of a frailty screening initiative with postoperative survival at 30,180, and 365 days. JAMA Surg. 2017;152(3):233-240.

42. Gleason LJ, Benton EA, Alvarez-Nebreda ML, Weaver MJ, Harris MB, Javedan H. FRAIL questionnaire screening tool and short-term outcomes in geriatric fracture patients. J Am Med Dir Assoc. 2017;18(12): 1082-1086.

43. Dal Moro F, Morlacco A, Motterle G, Barbieri L, Zattoni F. Frailty and elderly in urology: Is there an impact on post-operative complications? Cent European J Urol. 2017;70(2):197-205.
Clinical Interventions in Aging

\section{Publish your work in this journal}

Clinical Interventions in Aging is an international, peer-reviewed journal focusing on evidence-based reports on the value or lack thereof of treatments intended to prevent or delay the onset of maladaptive correlates of aging in human beings. This journal is indexed on PubMed Central, MedLine,

\section{Dovepress}

CAS, Scopus and the Elsevier Bibliographic databases. The manuscript management system is completely online and includes a very quick and fair peer-review system, which is all easy to use. Visit http://www.dovepress. com/testimonials.php to read real quotes from published authors. 